\title{
Wireless Based Automobile Parking Slot System
}

\section{Manoj Kumar Ojha}

\begin{abstract}
This paper deals with the study of wireless based automobile parking slot system. In today's conditions it is observed a sudden increase in parking in city areas, that is why the project aims to find a solution. People can easily view the full list of parking series in real or physical time on the internet server and can book the parking spaces requested depending on their accessibility. By making a reservation through this process, it not only reduces the time spend in searching parking area but also reduce the wastage of human efforts.
\end{abstract}

Keywords- wireless, parking slot, internet server, cloud, website, reservation area.

\section{INTRODUCTION}

With the rapid growth in population, the parking of automobile problems has also increased significantly. Therefore, an effective parking system would play an important part in saving big time and energy [1], [2]. With the help of the server, a user could view the available parking spaces and can book their places in advance of their own convenience. This system incorporates Wifi technology. This technology will allow the real-time position of the available park spaces to be made available to enable the customer to pre-purchase the available time to the resource itself [3], [4]. An internet server would be the interface where customers could plan the times. Once the spaces have been successfully sold, customers would be given RFID separately. So, buyers would be able to check in with their particular RFID [5]. As a result of this work, a great deal of customers would be saved. The heart of the project lies in the programming of the Arduino board. Arduino is enrolled in such a way that users will also have easy access to free parking spaces [6]. This project might be modernized with payment option. The total number of parking details is displayed in displaying unit. as a car arrives at the parking gate, the owner should pass an RFID based tag to the reading device of RFID [7]. The RFID reader then sends the information to a microcontroller, if the information is matched, the gate entry will be open. If the information is incorrect, the gate will be closed. The location of the vehicle can be detected by using the GPS system imbedded inside the user interface to prevent the parked vehicle from the robbery.

\section{PROPOSED SYSTEM}

In the system that is displayed, users must first visit the internet server page. The internet server would be the interface [8]. It would ask the user to start the process of booking parking area. The infrared reader would have been put at the parking spaces to help find out if a car is parked in the parking area or not. The availability of parking area is determined with the help of microcontroller installed in the vehicle so that it would become easy for the user to park the vehicle in the exact place. The radio frequency identifier detector (RFID) assist to the RFID reader in creating a separate code for each customer [9]. The main advantage of using RFID code is that it provides security to the customer and prevent the vehicle from being theft. By this manner, the user's time and strength will be saved greatly.

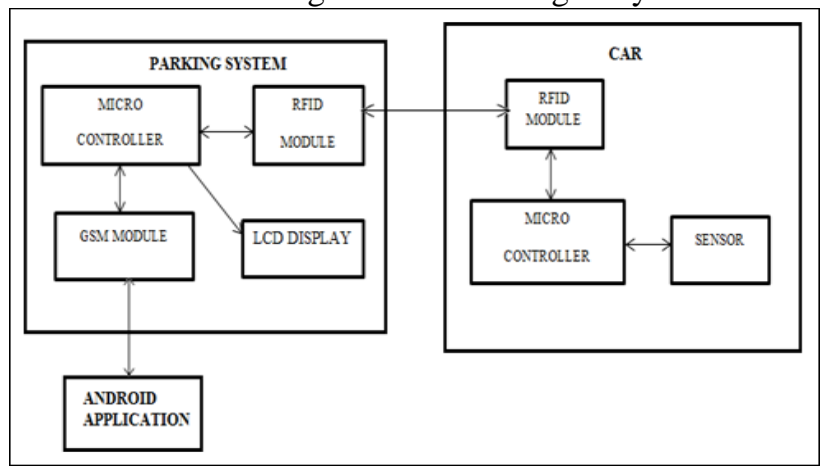

Fig.1 Block Diagram of Proposed System

For accessing the information of parking area an application is installed in the user interface such as smart phone to detect the parking slot wirelessly [10]. The controller receives the signal from the user interface to check the availability of vacant space and transmit back the signal by telling the user about the vacancy of the parking slot. Fig. 1 represents the two section first one is the parking section and other one is for vehicle section. Firstly, the infrared sensor that is installed in the parking slot will detects the parking space and notify the user for the same.

Table l. Comparison of different RFID systems

\begin{tabular}{|c|c|c|c|}
\hline & RF Code & Identec solutions & Aero Scout \\
\hline $\begin{array}{l}\text { Reading range } \\
\text { (outdoor indoor) }\end{array}$ & $100 \mathrm{~m}$ & $100 \mathrm{~m}$ & $200 \mathrm{~m} / 60 \mathrm{~m}$ \\
\hline $\begin{array}{l}\text { RSSI/TDOA } \\
\text { Measurability }\end{array}$ & Not possible & Not possible & Possible \\
\hline Not possible & $2 \mathrm{~g} / 12.5 \mathrm{~s}$ & $0.5 \mathrm{~s} \sim 60 \mathrm{~s}$ & $128 \mathrm{~ms} \sim 3.5 \mathrm{~h}$ \\
\hline Battery & $\begin{array}{l}\text { Not } \\
\text { replaceable }\end{array}$ & Not replaceable & Replaceable \\
\hline $\begin{array}{l}\text { Tag } \\
\text { programmability }\end{array}$ & $\begin{array}{l}\text { Not } \\
\text { programmable }\end{array}$ & $\begin{array}{l}\text { Transmission } \\
\text { interval } \\
\text { programmable }\end{array}$ & $\begin{array}{l}\text { Tranomission } \\
\text { interval } \\
\text { Programmable }\end{array}$ \\
\hline $\begin{array}{l}\text { On board } \\
\text { motion sensor }\end{array}$ & Available & Not available & Available \\
\hline
\end{tabular}

Published By:

Blue Eyes Intelligence Engineering

\& Sciences Publication 


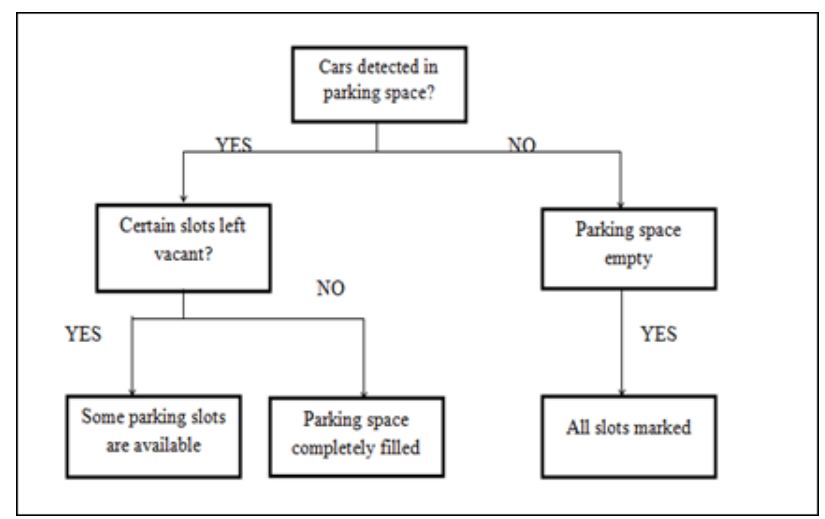

Figure 2. Algorithm for Detecting Parking Slot

If the parking slot is not empty then the microcontroller will send signal to the user interface through GSM module that the parking is full. If there is any vacant space left in the parking area, the controller will send the message by alerting the user about the vacancy in parking area. A GSM module is preferably used for transmitting and accepting the messages coming from or going to microcontroller. The GSM module is basically act as interface between user smart phone and a microcontroller. When the user sends any message to controller then the message goes to a microcontroller through the GSM module. Similarly, when the microcontroller has to send any information to the user smart phone the message is transferred through the GSM module.

\section{RESULT FROM SIMULATION AND HARDWARE}

The system is first design and implemented in the MATLAB simulation software and then developed in the form of hardware. Fig. 3 shows the simulation of parking system and fig. 4 and 5 shows the hardware implementation of the same.

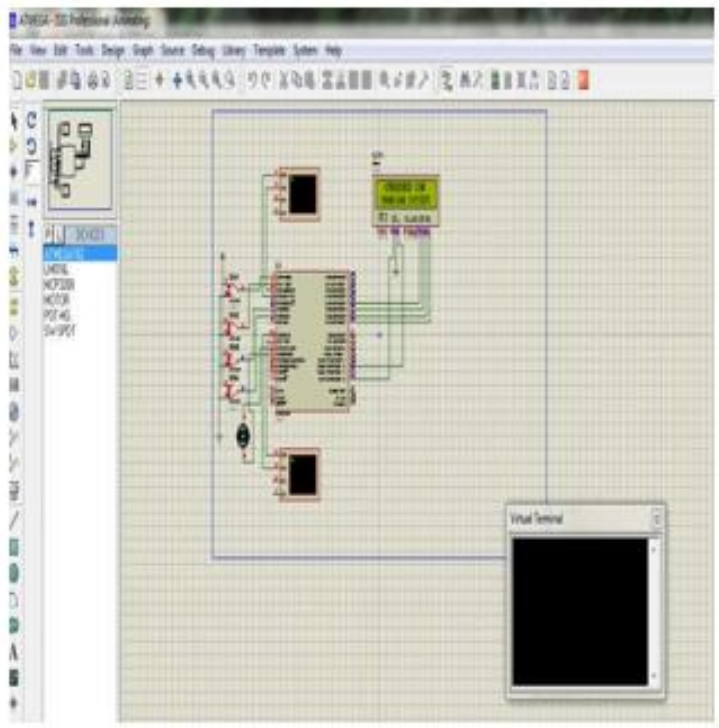

Figure 3. Vehicle parking system using Proteus

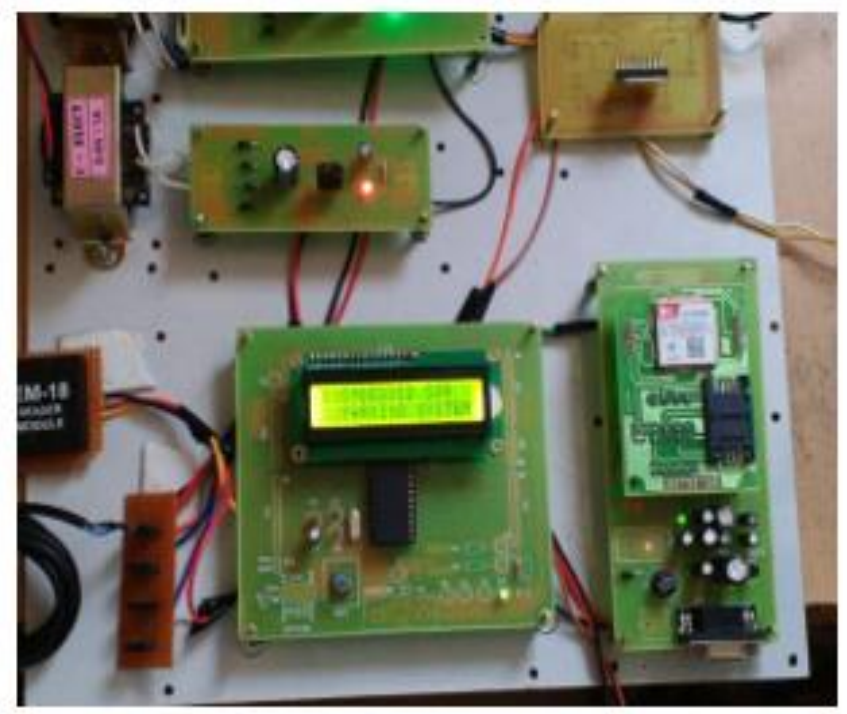

Figure 4. Embedded vehicle parking system

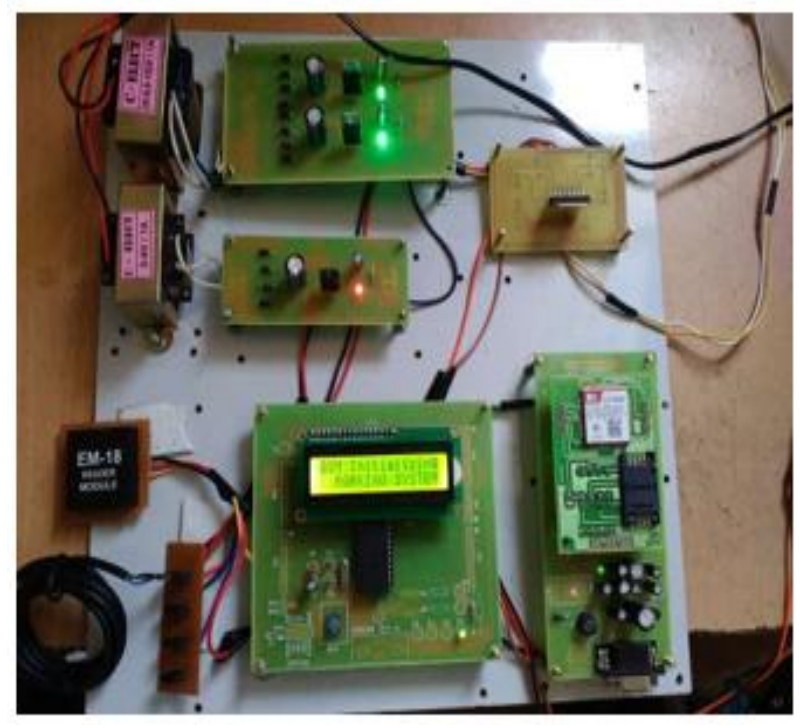

Figure 5. Gate model

\section{CONCLUSION}

In this paper the wireless based automobile parking slot system is first designed in the simulation software and then implemented in hardware. Most of the traffic in the city occurs due to the placing of vehicle in no parking area. This creates a lot of problem to the user as well as the traffic police to release traffic. Therefore, to eliminate this problem a wireless vehicle parking system is developed that is capable of detecting the vacant area or slot to park the vehicle and alert the user if found any vacancy. This system is also capable of real time monitoring of vehicle with the help of GPS module to avoid robbery or any misshaping

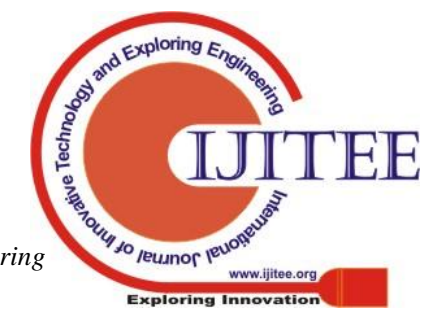




\section{REFERENCES}

1. F. J. Wu, Y. F. Kao, and Y. C. Tseng, "From wireless sensor networks towards cyber physical systems," Pervasive and Mobile Computing. 2011.

2. V. C. Gungor and G. P. Hancke, "Industrial wireless sensor networks: Challenges, design principles, and technical approaches," IEEE Trans. Ind. Electron., 2009.

3. Y. Hirakata, A. Nakamura, K. Ohno, and M. Itami, "Navigation system using ZigBee wireless sensor network for parking," in 2012 12th International Conference on ITS Telecommunications, ITST 2012, 2012.

4. S. A. Alkheder, M. M. Al Rajab, and K. Alzoubi, "Parking problems in Abu Dhabi, UAE toward an intelligent parking management system 'ADIP: Abu Dhabi Intelligent Parking,”” Alexandria Eng. J., 2016.

5. R. Grodi, D. B. Rawat, and F. Rios-Gutierrez, "Smart parking: Parking occupancy monitoring and visualization system for smart cities," in Conference Proceedings IEEE SOUTHEASTCON, 2016.

6. M. Aazam, I. Khan, A. A. Alsaffar, and E. N. Huh, "Cloud of Things: Integrating Internet of Things and cloud computing and the issues involved," in Proceedings of 2014 11th International Bhurban Conference on Applied Sciences and Technology, IBCAST 2014, 2014.

7. X. Jia, Q. Feng, T. Fan, and Q. Lei, "RFID technology and its applications in Internet of Things (IoT)," in 2012 2nd International Conference on Consumer Electronics, Communications and Networks, CECNet 2012 Proceedings, 2012.

8. E. Oriwoh, P. Sant, and G. Epiphaniou, "Guidelines for Internet of things deployment approaches - The thing commandments," in Procedia Computer Science, 2013.

9. B. M. Kumar Gandhi and M. Kameswara Rao, "A prototype for IoT based car parking management system for smart cities," Indian J. Sci. Technol., 2016.

10. G. Anusooya, J. C. Jackson, K. Sathyarajasekaran, and K. Kannan, "RFID based smart car parking system," Int. J. Appl. Eng. Res., 2017. 